\title{
Saccocalyx satureioides as corrosion inhibitor for carbon steel in acid solution
}

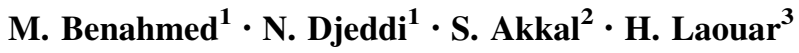

Received: 24 February 2015/ Accepted: 24 April 2016/Published online: 5 May 2016

(c) The Author(s) 2016. This article is published with open access at Springerlink.com

\begin{abstract}
The inhibitory effect of the crude ethyl acetate extract of Saccocalyx satureioides was estimated on the corrosion of carbon steel (X52) in $1 \mathrm{M} \mathrm{HCl}$ solution sing weight loss measurement, potentiodynamic polarization, electrochemical impedance spectroscopy and scanning electron microscopy techniques. Potentiodynamic polarization curves indicated that the plants extract behaves as a mixed-type inhibitor. The adsorption of the inhibitor on the carbon steel surface was found to follow Freundlich adsorption isotherm. The free energies, enthalpies and entropies for the adsorption and dissolution process were discussed in details. The inhibiting action increases with increasing concentration of the extract. The results obtained show that the extract of the aerial parts of Saccocalyx satureioides could serve as an effective corrosion inhibitor of carbon steel (X52) in hydrochloric acid medium.
\end{abstract}

Keywords Carbon steel X52 - Saccocalyx satureioides . Inhibition

M. Benahmed

riad43200@yahoo.fr

1 Laboratoire des Molécules Bioactives et Applications, Université Larbi Tébessi, Route de Constantine, 12000 Tébessa, Algeria

2 Laboratoire de Phytochimie et Analyses physicochimiques et Biologiques, Département de Chimie, Faculté de Sciences exactes, Université Mentouri Constantine, Route d'Ain el Bey, 25000 Constantine, Algeria

3 Laboratoire de Valorisation des Ressources Naturelles Biologiques, Département de Biologie, Université Ferhat Abbas de Sétif, Sétif, Algeria

\section{Introduction}

Metals and alloys are frequently used in industrial applications due to their convenience and low cost. Among these, carbon steel is one of the most important alloys which are continually used. Unfortunately, it suffers serious acid corrosion.

To prevent carbon steel against acid corrosion, inhibitors are often used. Unfortunately, some of them are not environmentally friendly. Therefore, the uses of ecofriendly and biodegradable products are preferred. Recently, many published works shown that some naturally occurring substances have corrosion inhibitor properties for different metals in various environments [1-6].

Saccocalyx satureioides (Lamiaceae) is an Algerian endemic species, which grows in the dunes of the predesert area. This plant is $20-100 \mathrm{~cm}$ high. Its flowers can be white, rose or crimson [7]. Various studies reported the chemical composition of $S$. satureioides oils obtained from the same plant but collected in North and Northeast of Algeria. Some of these investigation reported that this species reveal a strong antimicrobial activity against Staphylococcus aureus, Escherichia coli and Klebsiella [810]. Moreover, a research work reported by Mohamadi et al. [11] revealed the identification of seventeen compounds from $S$. satureioides: piceol, vanillin, ferulic aldehyde, 3,3'-bis (3,4-dihydro-4-hydroxy-6,8-dimethoxy-2H1-benzopyran), 3,3-bis (3,4-dihydro-4-hydroxy-6-methoxy2H-1-benzopyran), dimethylcaffeic acid, balanophonin, 7-methyl-sudachitin, caffeicacid, $p$-coumaric acid, isoscutellarein-7- $O$-[ $\beta$-D-allopyranosyl- $(1 \rightarrow 2)] \beta$-D-glucopyranoside, isoscutellarein-7- $O$-[ $\beta$-D-allopyranosyl- $(1 \rightarrow 2)]-$ $6^{\prime \prime}$-O-acetyl- $\beta$-D-lucopyranoside, isoscutellarein-7- $O$ [6 $6^{\prime \prime \prime}$ - $O$-acetyl- $\beta$-D-allopyranosyl- $\left.(1 \rightarrow 2)\right]-\beta$-D-glucopyranoside, quercetin, isoscutellarein-7- $O$-[6 $6^{\prime \prime \prime}-O$-acetyl- $\beta$-D- 
allo pyranosyl-( $1 \rightarrow 2)]-6^{\prime \prime}$ - $O$-acetyl-D $\beta$-glucopyranoside, apigenin-7- $O$ - $\left[6^{\prime \prime}\right.$-trans- $p$-coumaroyl $]-\beta$-D-glucopyranoside and sideritiflavone.

In this work, we describe the testing of ethyl acetate extract parts $S$. satureioides as corrosion inhibitor for carbon steel (X52) in $\mathrm{HCl}$ solution, using weight loss and electrochemical techniques, such as potentiodynamic polarization and electrochemical impedance spectroscopy (EIS).

\section{Experimental}

\section{Plant material}

The aerial part of Saccocalyx satureioides was picked up during June 2011, in El Masrane near Djelfa, Algeria. After identification, a voucher specimen was deposited in the Herbarium of the Museum of natural history of Nice city (Voucher number B-6309).

\section{Extraction and isolation}

The air-dried aerial parts of S. satureioides (800 g) were extracted three times with boiling methyl alcohol (70\%). The hydro-alcoholic solutions were concentrated in vacuum to aridness and the residue was dissolved in hot water and kept overnight at room temperature. After filtration, the aqueous solution was successively treated with ethyl acetate and $n$-butanol, and then their extracts were concentrated to dryness $[12,13]$.

\section{Materials}

Carbon steel (X52), with the chemical composition displayed in Table 1, was used in this study. Coupons of carbon steel (X52) with dimensions $1.0 \times 0.8 \times 0.4 \mathrm{~cm}$ were used for weight loss measurements. For electrochemical measurements, a steel cube embedded in epoxy resin, leaving an exposed surface area of $0.8 \mathrm{~cm}^{2}$ as a working electrode. The coupons were abraded with different grade of emery papers, (600, 800, 1200 and 2000), degreased with acetone and rinsed with distillated water, before its immersion in $1 \mathrm{M} \mathrm{HCl}$ with and without the addition of different concentrations of Saccocalyx satureioides ethyl acetate extract (SSE).

\section{Corrosion tests}

\section{Weight loss measurements}

Weight loss measurements were conducted under total immersion in stagnant aerated condition using $250 \mathrm{~mL}$ capacity beakers containing $150 \mathrm{ml}$ test solution at 293-323 K maintained in a thermostated water bath. Carbon steel (X52) coupons were weighed and suspended in the previous beakers. After $6 \mathrm{~h}$, the coupons were taken out, washed in distilled water, dried and then weighed. From the weight loss values, corrosion rates $(\mathrm{Cr})$, surface coverage and the inhibition efficiency IE (\%) were calculated using the expressions [14]:

$\mathrm{Cr}=\frac{\Delta W}{A t}$

where $\Delta W$ is the weight loss, $A$ is the sectional area of carbon steel (X52), $t$ is the exposure time.

$\theta=\frac{\mathrm{Cr}_{0}-\mathrm{Cr}_{i}}{\mathrm{Cr}_{0}}$

$\mathrm{IE}(\%)=\theta \times 100$

where $\theta$ the surface coverage, $\mathrm{Cr}_{0}$ and $\mathrm{Cr}_{i}$ are the corrosion rates of the carbon steel (X52) coupons in absence and presence of inhibitor, respectively.

\section{Potentiodynamic polarization measurement}

All electrochemical measurements were carried out using a computer controlled Voltalab PGZ 301 instrument with Voltamaster software at room temperature, without and with the addition of different concentrations of SSE to $1 \mathrm{M}$ $\mathrm{HCl}$ solution. Open circuit potential $\left(E_{\mathrm{ocp}}\right)$, was measured for $60 \mathrm{~min}$ to allow stabilization of the steady state potential. The potential of the potentiodynamic polarization curves ranged from a cathodic potential of $-100 \mathrm{mV}$ to an anodic potential of $+100 \mathrm{mV}$ versus OCP at a scan rate of $1 \mathrm{mV} \mathrm{s}^{-1}$. The inhibition efficiency IE (\%) was calculated using the relation:

$\mathrm{IE}(\%)=\frac{i_{\text {corr }}-i_{\text {corr }_{(i)}}}{i_{\text {corr }}} \times 100$

where $i_{\text {corr }}$ and $i_{\text {corr }(i)}$ are the corrosion current density without and with the addition of the inhibitor, respectively.
Table 1 Chemical composition of carbon steel (X52)

\begin{tabular}{lllllll}
\hline Composition & $\mathrm{C}$ & $\mathrm{Mn}$ & $\mathrm{Si}$ & $\mathrm{S}$ & $\mathrm{P}$ & $\mathrm{Fe}$ \\
\hline $\mathrm{Wt} \%$ & 0.1039 & 0.9710 & 0.1261 & 0.0021 & 0.0020 & Remainder \\
\hline
\end{tabular}




\section{Electrochemical impedance spectroscopy}

Electrochemical impedance spectroscopy measurements were carried out using the same instrument described above with the open circuit potential. Every sample was immersed for 30 min over a frequency range of $100 \mathrm{kHz}-$ $0.01 \mathrm{~Hz}$ with applied potential signal amplitude of $5 \mathrm{mV}$. The percentage inhibition efficiency IE (\%) was calculated from,

$\mathrm{IE}(\%)=\frac{R_{i}-R_{0}}{R_{i}} \times 100$

where $R_{0}$ and $R_{i}$ are charge transfer resistance of carbon steel (X52) in uninhibited and inhibited solutions, respectively.

\section{Scanning electron microscope (SEM)}

The specimens used to examine the surface morphology were prepared as described above then immersed in 1 $\mathrm{M} \mathrm{HCl}$ in the absence and presence of $900 \mathrm{mg} \mathrm{L}^{-1} \mathrm{SSE}$ at room temperature. SEM images were taken for specimens that have been submerged for $6 \mathrm{~h}$. The SEM used was a JEOL model JSM 6390LV.

\section{Results and discussion}

\section{Weight loss measurements}

Corrosion rate and inhibition efficiency of carbon steel (X52) in $1 \mathrm{M} \mathrm{HCl}$ solution at 293-323 $\mathrm{K}$ in the absence and presence SSE were shown in Table 2. From the values obtained, it is clear that the presence of inhibitor leads to a reduction of the corrosion rate. It is indicated that inhibition efficiency of carbon steel (X52) rises with increasing SSE concentration up to $87 \%$ at 293 K (Fig. 1a). Several scientists in their studies (Table 3 ) reported similar results [2, 4, 6, 15-19], which confirm that the SSE act as effective inhibitors. The evolution in inhibition efficiency may be attributed to the adsorption of the particles at the carbon steel (X52) surfaces [20]. As the temperature increases, the corrosion rate $(\mathrm{Cr})$ increases and inhibition efficiency decreases (Fig. 1b). This suggests a probable desorption of some adsorbed inhibitor from the steel surface at higher temperature. This behavior indicates that the phytochemical components are physically adsorbed on the carbon steel surface [14].

\section{Adsorption isotherm}

The degrees of surface coverage $(\theta)$ for different inhibitor concentrations were calculated by weight loss data. The

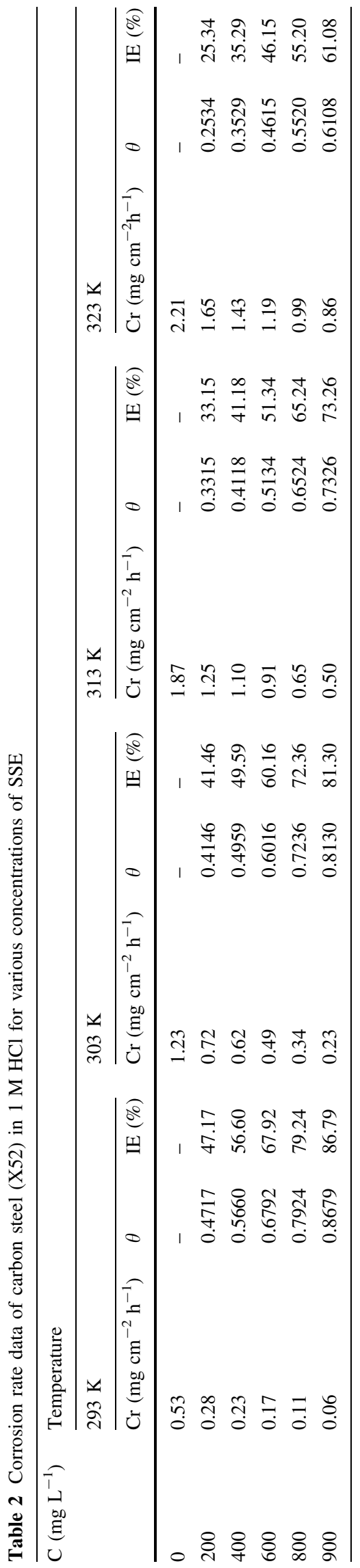


surface coverage values were fitted to different adsorption isotherm models, including Langmuir, Frumkin, Freundlich and Temkin isotherms, and the best results
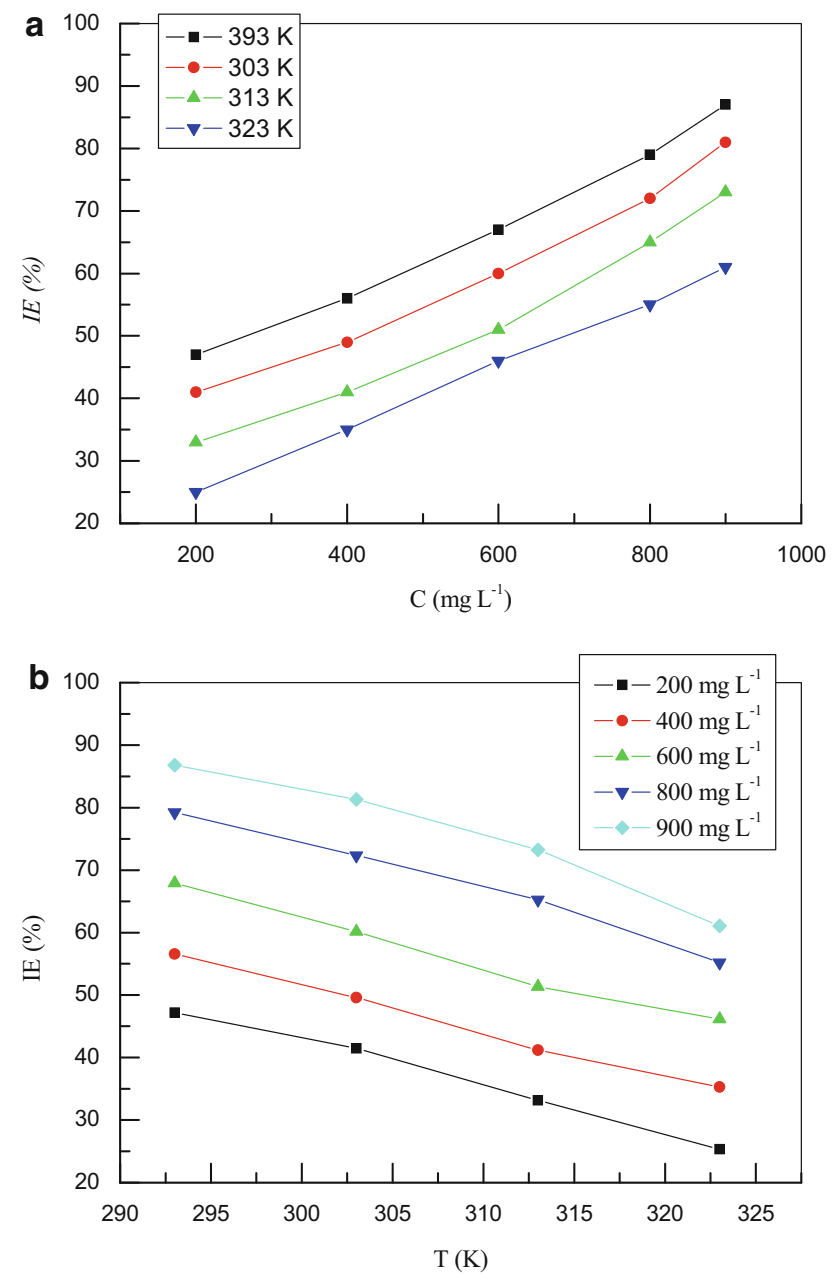

Fig. 1 Variation of inhibition efficiency of SSE in $1 \mathrm{M} \mathrm{HCl}$ with: a extract concentration, b temperature revealed by the correlation coefficient $\left(r^{2}\right)$ were obtained with the Freundlich adsorption isotherm for all considered temperatures. Figure 2 shows the plot of $\log \theta$ versus $\log C$ for SSE at $293-323 \mathrm{~K}$.

Freundlich adsorption isotherm could be represented using the following equation:

$\log \theta=\log K_{\text {ads }}+n \log C$

where $0<n<1$; $\theta$ is the surface coverage, $C$ is the inhibitor concentration and $K_{\text {ads }}$ is the adsorption constant. The $K_{\text {ads }}$ values presented in the Table 4 were calculated from the intercept lines on the $\log \theta$ axis.

Table 4 shows that $K_{\text {ads }}$ values decrease with increasing temperature. This result can be interpreted in a way that the temperature rise up induce desorption of some adsorbed components of the extracts from the surface. It is indeed consistent with the proposed physisorption mechanism [14].

\section{Thermodynamic parameters}

The standard adsorption free energy $\left(\Delta G_{\text {ads }}^{0}\right)$ can be calculated on the basis equation [21, 22]:

$\Delta G_{\mathrm{ads}}^{0}=-R T \ln \left(\mathrm{C}_{\mathrm{H}_{2} \mathrm{O}} \cdot K_{\mathrm{ads}}\right)$

where $R$ is the gas constant, $T$ the absolute temperature $(\mathrm{K})$ and $\mathrm{C}_{\mathrm{H} 2 \mathrm{O}}$ is the concentration of water expressed in $\mathrm{mg} \mathrm{L}^{-1}$ with an approximate value of $10^{6}$. It should be noted that the unit of $\mathrm{C}_{\mathrm{H} 2 \mathrm{O}}$ lies in that of $K_{\text {ads }}$ [23].

The standard adsorption enthalpy $\left(\Delta H_{\mathrm{ads}}^{0}\right)$ could be calculated using Van't Hoff equation [25]:

$\frac{\delta \ln K_{\mathrm{ads}}}{\delta T}=\frac{\Delta H_{\mathrm{ads}}^{0}}{R T^{2}}$.

Equation (6) can be rewritten as:

$\ln K_{\mathrm{ads}}=\frac{-\Delta H_{\text {ads }}^{0}}{R T}+I$

Table 3 Critical concentration and percentage inhibition efficiency for different plants extracts

\begin{tabular}{|c|c|c|c|c|}
\hline Natural products & Acidic media & Metal exposed & Optimum concentration & Highest of IE (\%) \\
\hline Diethyl ether extract of Ptychotis verticillata [15] & $1 \mathrm{M} \mathrm{HCl}$ & Mild steel & $0.25 \mathrm{~g} \mathrm{~L}^{-1}$ & 75.00 \\
\hline Ethyl acetate extract of Ptychotis verticillata [15] & & & $0.5 \mathrm{~g} \mathrm{~L}^{-1}$ & 86.00 \\
\hline Pelargonium extract [16] & $1 \mathrm{M} \mathrm{HCl}$ & Mild steel & $10 \mathrm{~mL} \mathrm{~L}^{-1}$ & 76.79 \\
\hline Geissospermum laeve extract [2] & $1 \mathrm{M} \mathrm{HCl}$ & C38 steel & $100 \mathrm{mg} \mathrm{L}^{-1}$ & 92.00 \\
\hline Mentha pulegium [17] & $1 \mathrm{M} \mathrm{HCl}$ & Steel & $2.76 \mathrm{~g} \mathrm{~L}^{-1}$ & 78.00 \\
\hline Henna extract [18] & $1 \mathrm{M} \mathrm{HCl}$ & C-Steel & $3000 \mathrm{mg} \mathrm{L}^{-1}$ & 88.42 \\
\hline Alkaloid extract of G. ouregou [4] & $0.1 \mathrm{M} \mathrm{HCl}$ & Low carbon steel & $250 \mathrm{mg} \mathrm{L}^{-1}$ & 88.00 \\
\hline Alkaloid extract of S. tinctoria [4] & & & & 90.00 \\
\hline Alkaloids extract of Oxandra asbeckii [19] & $1 \mathrm{M} \mathrm{HCl}$ & C38 steel & $100 \mathrm{mg} \mathrm{L}^{-1}$ & 87.00 \\
\hline Bark extract of Neolamarckia cadamba [6] & $1 \mathrm{M} \mathrm{HCl}$ & Mild steel & $5 \mathrm{mg} \mathrm{L}^{-1}$ & 82.00 \\
\hline Leaves extract of Neolamarckia cadamba [6] & & & & 84.00 \\
\hline Pure alkaloid of Neolamarckia cadamba [6] & & & & 83.00 \\
\hline
\end{tabular}




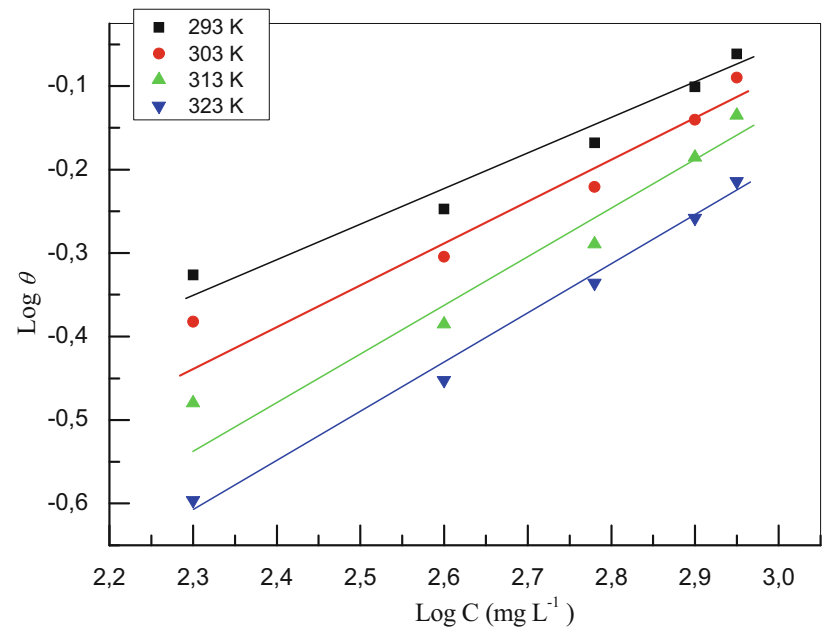

Fig. 2 Freundlich adsorption plot for carbon steel (X52) in $1 \mathrm{M} \mathrm{HCl}$ containing different concentration of SSE

Table 4 Parameters of the linear regression

\begin{tabular}{lll}
\hline Temperature $(\mathrm{K})$ & $r^{2}$ & $k_{\text {ads }}\left(\mathrm{L} \mathrm{mg}^{-1}\right)$ \\
\hline 293 & 0.982 & 0.0543 \\
303 & 0.972 & 0.0387 \\
313 & 0.973 & 0.0198 \\
323 & 0.996 & 0.0112 \\
\hline
\end{tabular}

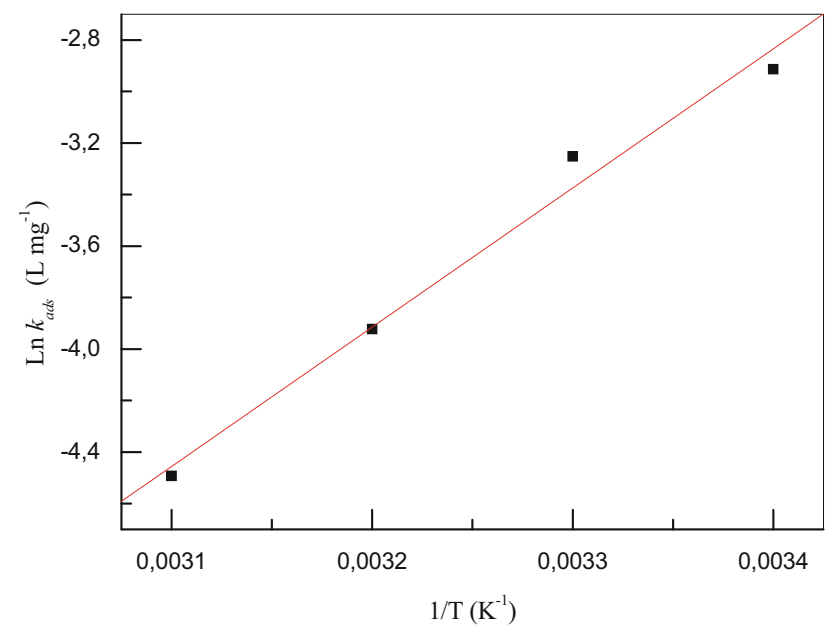

Fig. 3 Straight line of $\ln K_{\text {ads }}$ versus $1 / T$ for SSE

where $I$ is a constant of integration. Figure 3 presents straight lines of $\ln K_{\text {ads }}$ versus $1 / T$ with good linear relationship (the linear correlation coefficients is 0.9970). $\Delta H_{\text {ads }}^{0}$ values calculated from the slope $\left(-\frac{\Delta H_{\text {ads }}^{0}}{R}\right)$ and listed in Table 5.

From the obtained values of $\Delta G_{\text {ads }}^{0}$ and $\Delta H_{\text {ads }}^{0}$ parameters, the standard adsorption entropy $\left(\Delta S_{\mathrm{ads}}^{0}\right)$ can be
Table 5 Standard thermodynamic parameters of the adsorption of SSE in $1 \mathrm{M} \mathrm{HCl}$ solution

\begin{tabular}{llll}
\hline$T(\mathrm{~K})$ & $\Delta G_{\text {ads }}^{0}\left(\mathrm{~kJ} \mathrm{~mol}^{-1}\right)$ & $\Delta H_{\text {ads }}^{0}\left(\mathrm{~kJ} \mathrm{~mol}^{-1}\right)$ & $\Delta S_{\text {ads }}^{0}\left(\mathrm{~J} \mathrm{~mol}^{-1} \mathrm{~K}^{-1}\right)$ \\
\hline 293 & -26.56 & -44.94 & -62.73 \\
303 & -26.61 & & -60.49 \\
313 & -25.74 & -61.34 \\
323 & -25.04 & -61.61 \\
\hline
\end{tabular}

calculated using the thermodynamic Gibbs-Helmholtz equation:

$\Delta S_{\mathrm{ads}}^{0}=\frac{\Delta H_{\mathrm{ads}}^{0}-\Delta G_{\mathrm{ads}}^{0}}{T}$

All thermodynamic parameters are recorded in Table 5 . The negative values of $\Delta G_{\text {ads }}^{0}$ specify the spontaneity of the adsorption process [20]. In the present work, the calculated value of the adsorption free energy lies between -25.04 and $-26.61 \mathrm{~kJ} \mathrm{~mol}^{-1}$. It is less than the $-40 \mathrm{~kJ} \mathrm{~mol}^{-1}$ required for chemical adsorption. Allows with the decrease of IE (\%) with increasing temperature confirm the mechanism of physical adsorption [18]. The negative sign of $\Delta H_{\text {ads }}^{0}$ shows that the adsorption of inhibitor is an exothermic process $[25,26]$. For physisorption, $\Delta G_{\text {ads }}^{0}$ is in the order of $40 \mathrm{~kJ} \mathrm{~mol}^{-1}$ while for chemisorption, $\Delta H_{\mathrm{ads}}^{0}$ approaches $100 \mathrm{~kJ} \mathrm{~mol}^{-1}$ [27].

\section{Activation parameters of the corrosion process}

The temperature has a great effect on the rate electrochemical corrosion of metal. It is apparent from the Fig. 1b, that inhibition efficiency declines with increasing temperature. The reliance of corrosion rate on temperature can be stated by the Arrhenius equation [19]:

$\ln \mathrm{Cr}=-\frac{\mathrm{Ea}}{R T}+\ln D$

$\mathrm{Ea}$ is the apparent activation energy of the carbon steel (X52) dissolution and $D$ is the Arrhenius pre-exponential factor. The logarithm of the $\mathrm{Cr}$ versus $1 / T$ can be characterized by straight lines and the activation energy values were calculated from Arrhenius plots: (Fig. 4a).

The values of activation energy enumerated in Table 6 are higher in the presence of the SSE than in its absence. It may be attributed to the geometric blocking effect of adsorbed inhibitive species on the metal surface [28]. Further inspection of Table 6 also revealed that Ea increases with increase in SSE concentration. This means that the corrosion reaction will further be pushed to surface sites that are characterized by progressively higher values of $\mathrm{Ea}$ in the presence of extracts [29]. 

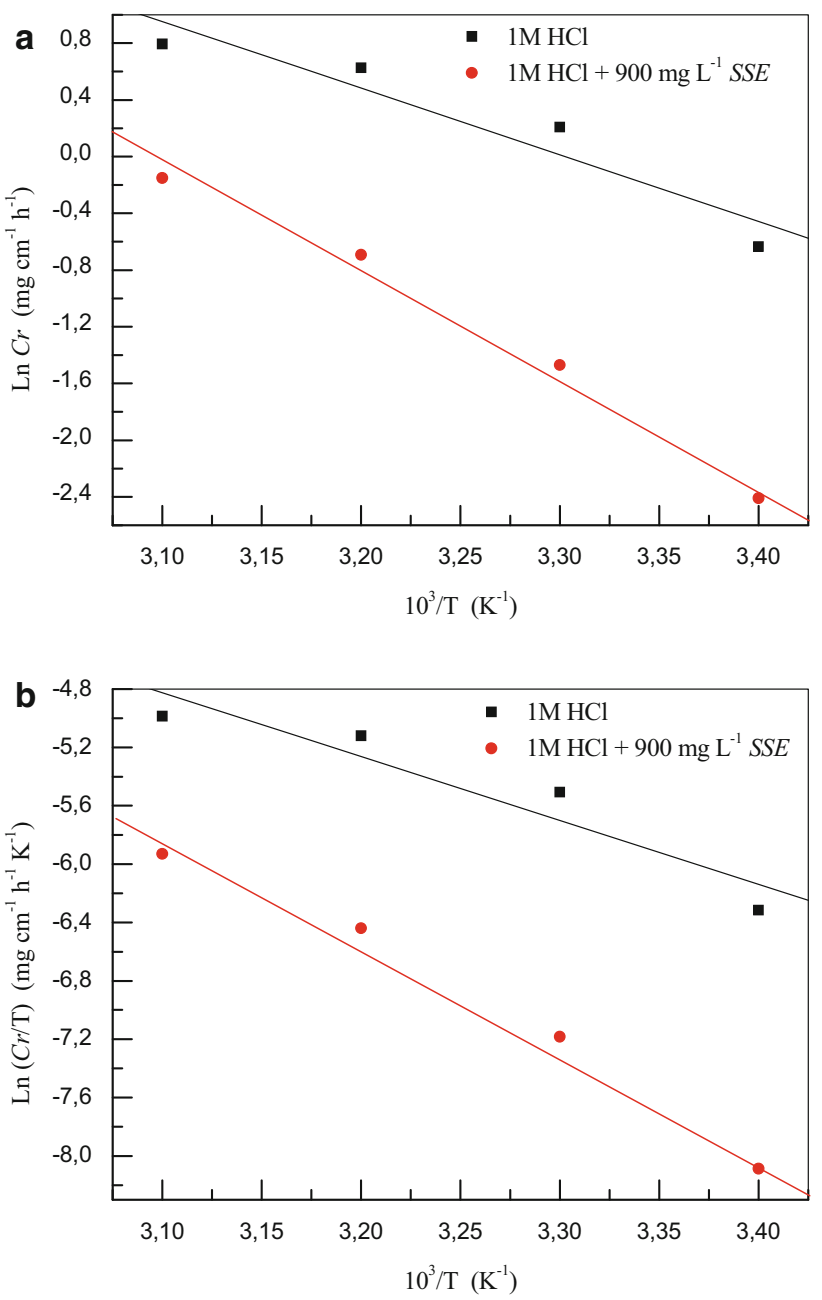

Fig. 4 Arrhenius plots related to the corrosion rate for carbon steel (X52) in $1 \mathrm{M} \mathrm{HCl}$ without and with $900 \mathrm{mg} \mathrm{L}^{-1}$ of SSE. a lnCr vs. 1/ $T, \mathbf{b} \ln (\mathrm{Cr} / T)$ vs. $1 / T$

Table 6 Activation parameters $E \mathrm{a}, \Delta H_{\mathrm{a}}^{0}$ and $\Delta S_{\mathrm{a}}^{0}$ for carbon steel (X52) in $1 \mathrm{M} \mathrm{HCl}$ at different concentrations of SSE at different temperatures

\begin{tabular}{llll}
\hline Conc. $\left(\mathrm{mg} \mathrm{L}^{-1}\right)$ & $\mathrm{Ea}\left(\mathrm{kJ} \mathrm{mol}^{-1}\right)$ & $\begin{array}{l}\Delta H_{\mathrm{a}}^{0} \\
\left(\mathrm{~kJ} \mathrm{~mol}^{-1}\right)\end{array}$ & $\begin{array}{l}10^{-1} \Delta S_{\mathrm{a}}^{0} \\
\left(\mathrm{~J} \mathrm{~mol}^{-1} \mathrm{~K}^{-1}\right)\end{array}$ \\
\hline 0 & 39.10 & 36.39 & 27.02 \\
200 & 50.93 & 48.22 & 30.53 \\
400 & 50.35 & 47.65 & 30.16 \\
600 & 53.68 & 50.97 & 31.06 \\
800 & 60.18 & 57.47 & 32.90 \\
900 & 62.75 & 60.06 & 33.53 \\
\hline
\end{tabular}

The enthalpy, $\Delta H_{\text {ads }}^{0}$ and entropy, $\Delta S_{\text {ads }}^{0}$ of activation for the corrosion process, the alternative formulation of Arrhenius equation was used [28, 29]:

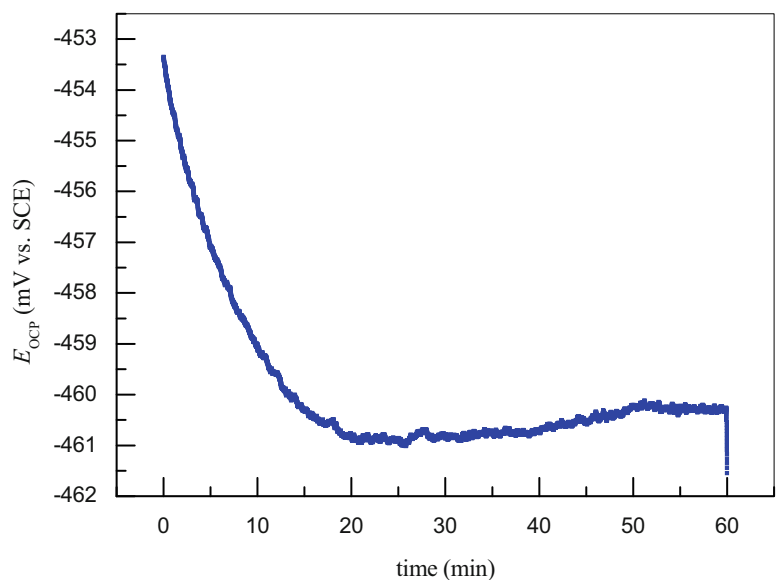

Fig. $5 E_{\mathrm{OCP}}$-time curve for carbon steel (X52) in $1 \mathrm{M} \mathrm{HCl}$

$\ln \mathrm{Cr}=\frac{R T}{h \mathrm{~N}_{\mathrm{a}}} \exp \frac{\Delta S_{\mathrm{a}}}{R} \exp \left(-\frac{\Delta H_{\mathrm{a}}}{R T}\right)$

where $h$ is the Planck's constant, $N_{\mathrm{a}}$ is Avogadro's number. A plot of $\frac{\ln \mathrm{Cr}}{T}$ vs. $\frac{1}{T}$ gave a straight line (Fig. $4 \mathrm{~b}$ ) with a slope of $-\frac{\Delta H}{R T}$ and an intercept of $\ln \frac{R}{N_{\mathrm{a}} h}+\Delta S_{\mathrm{a}}$, from which the values of $\Delta S_{\mathrm{a}}^{0}$ and $\Delta H_{\mathrm{a}}$ were calculated and registered in Table 6. The positive signs of enthalpies indicate the endothermic nature of the dissolution process [30].

The values of $\Delta S_{\mathrm{a}}^{0}$ given in Table 6 are positive and get improved in the presence of extracts. This behavior can be explicated as a result of the replacement process of water molecules during adsorption of SSE on the steel surface [27]. This observation is in agreement with many studies that have been reported by several authors [31-35].

\section{Open circuit potential measurement}

Figure 5 presents the variation of the open circuit potential $\left(E_{\mathrm{OCP}}\right)$ of the carbon steel (X52) vs time in $1 \mathrm{M} \mathrm{HCl}$ solution. Apparently, $E_{\mathrm{OCP}}$ remains almost unchanged, which indicate that the working electrode (WE) attains the steady state.

\section{Polarization measurement}

The anodic and cathodic polarization curves of carbon steel (X52) in $1 \mathrm{M} \mathrm{HCl}$ solution devoid and containing increasing concentrations of SSE are shown in Fig. 6. The respective kinetic parameters derived from the above plots are given in Table 7. It was demonstrated from the data that the addition of SSE shrank the corrosion current density $\left(i_{\text {corr }}\right)$. The decrease may be due to the adsorption of the inhibitor on metal/acid interface [35].

In existence of SSE both cathodic and anodic Tafel slopes $\left(\beta_{\mathrm{c}}, \beta_{\mathrm{a}}\right)$ decrease. This result indicates that the SSE 


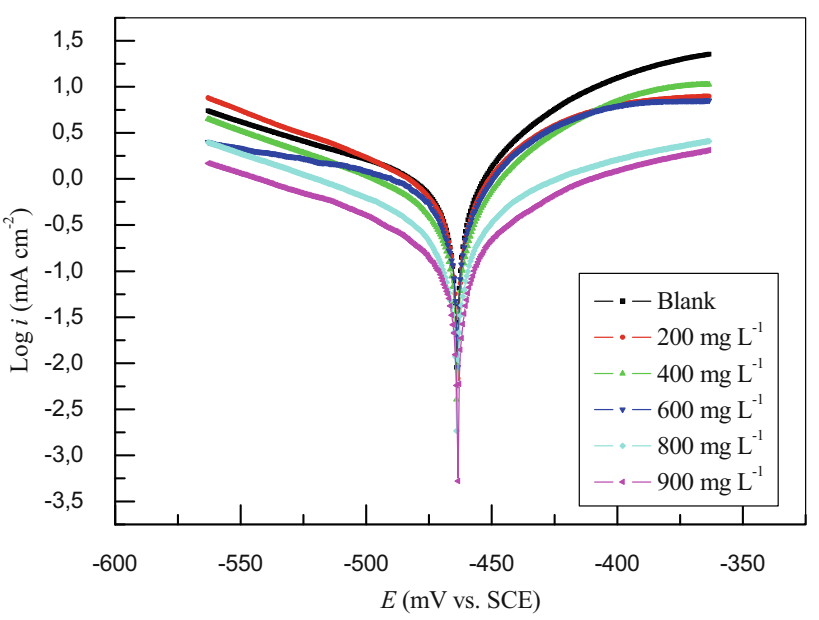

Fig. 6 Potentiodynamic polarization curves for carbon steel (X52) in $1 \mathrm{M} \mathrm{HCl}$ containing different concentrations of SSE

is a mixed-type inhibitor acting on both hydrogen evolution reaction and metal dissolution [36]. $E_{\text {corr }}$ nearly does not change in the presence of SSE. According to $\mathrm{Li}$ and Moretti $[24,37]$, the inhibition category belongs to geometric blocking effect. That is, the inhibition action manifest through the reduction of the reaction area on the surface of the corroding metal [23].

\section{Electrochemical impedance spectroscopy}

The corrosion of carbon steel (X52) in $1 \mathrm{M} \mathrm{HCl}$ solution in the presence of plant extract was investigated by EIS at room temperature after an exposure period of $30 \mathrm{~min}$. Impedance graphs (Fig. 7) are obtained for frequency range $100 \mathrm{kHz}-0.01 \mathrm{~Hz}$ at the open circuit potential for steel in $1 \mathrm{M} \mathrm{HCl}$ in absence and presence of SSE, and the values of charge transfer resistance $\left(R_{\mathrm{ct}}\right)$ and double-layer capacitance $\left(C_{\mathrm{dl}}\right)$ are presented in Table 8. Figure 7 showed that the impedance spectra display only one capacitive loop, which indicated that the corrosion of steel is mainly controlled by a charge transfer process [29, 38]. It is also clear that these are not impeccable semicircles and this difference has been attributed to frequency dispersion and the heterogeneity of the metal surface [19]. On the other hand, it is clear from the plots that the size of these

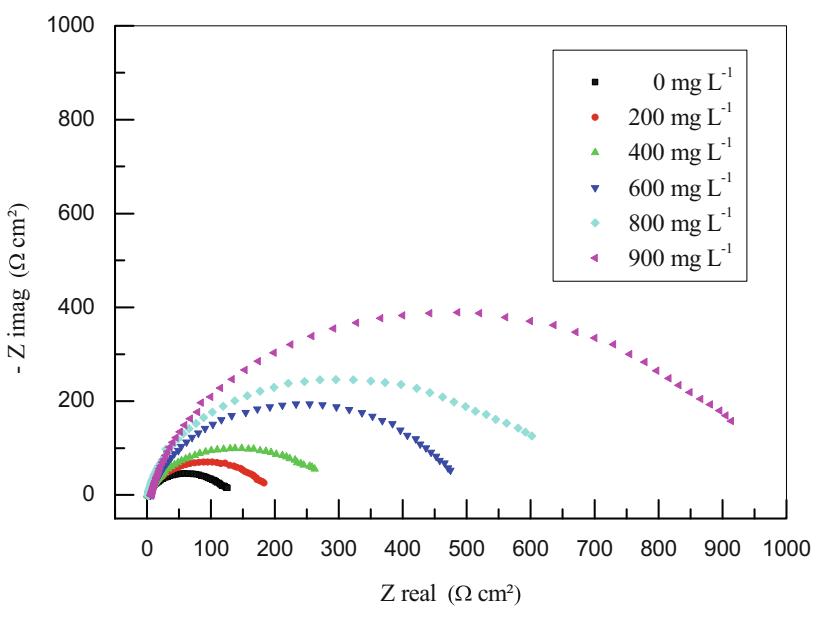

Fig. 7 Nyquist plots for carbon steel (X52) in $1 \mathrm{M} \mathrm{HCl}$ containing different concentrations of SSE

loops raises on increasing extract concentration. This suggests that the formed inhibitive film was strengthened by the addition of plant extract [39].

The impedance spectra for Nyquist plots were analyzed by fitting to equivalent circuit model (Fig. 8), which was used to describe carbon steel/solution interface. A simple electrical equivalent circuit (EEC) has been proposed to model the experimental data. In this EEC, $R_{1}$ is the solution resistance, $R_{\mathrm{ct}}$ is the charge transfer resistance and $Q$ is identified with the capacity. Generally, when a non-ideal frequency reply is present, it is usually accepted to replace the double-layer capacitance by constant phase element (CPE) [36]. Excellent fit with this model was obtained for all experimental data. As an example, the Nyquist plots for $1 \mathrm{M} \mathrm{HCl}$ alone and at $900 \mathrm{mg} \mathrm{L}^{-1}$ are presented in Figs. 9 and 10 , respectively.

The values of the $C_{\mathrm{dl}}$ can be calculated from CPE parameter and $R_{\mathrm{ct}}$ according to the following equation [21]:

$C_{\mathrm{dl}}=R_{\mathrm{ct}}^{\frac{1-n}{n}} Q^{\frac{1}{n}}$

$n$ is the deviation parameter of the CPE: $0 \leq 0 \leq 1$, for $n=1$, Eq. (13) agrees to the impedance of an ideal capacitor, where $Q$ is identified with the capacity.

The electrochemical parameters including $R_{\mathrm{ct}}, Q$ and $n$, obtained from fitting are listed in Table 8. In the Table 8, are also given the calculated "double-layer capacitance"
Table 7 Potentiodynamic polarizations parameters of carbon steel (X52) in $1 \mathrm{M} \mathrm{HCl}$ for various concentrations of SSE

\begin{tabular}{lllccc}
\hline Conc. $\left(\mathrm{mg} \mathrm{L}^{-1}\right)$ & $-E_{\text {corr }}(\mathrm{mV} / \mathrm{SCE})$ & $i_{\text {corr }}\left(\mathrm{mA} \mathrm{cm}^{-2}\right)$ & $\beta_{\mathrm{a}}\left(\mathrm{mV} \mathrm{Dec}^{-1}\right)$ & $-\beta_{\mathrm{c}}\left(\mathrm{mV} \mathrm{Dec}^{-1}\right)$ & $\mathrm{IE}(\%)$ \\
\hline 0 & 463.8 & 1.5671 & 102.4 & 151.0 & - \\
200 & 463.5 & 0.7924 & 83.2 & 119.7 & 49 \\
400 & 463.8 & 0.6471 & 73.4 & 113.0 & 59 \\
600 & 465.3 & 0.5238 & 50.4 & 114.8 & 66 \\
800 & 462.6 & 0.3263 & 48.7 & 108.0 & 79 \\
900 & 462.9 & 0.2012 & 45.3 & 92.7 & 87 \\
\hline
\end{tabular}


Table 8 Electrochemical impedance spectroscopy parameters of carbon steel (X52) in $1 \mathrm{M} \mathrm{HCl}$ for various concentrations of SSE

\begin{tabular}{llllll}
\hline Conc. $\left(\mathrm{mg} \mathrm{L}^{-1}\right)$ & $R_{\mathrm{ct}}\left(\Omega \mathrm{cm}^{2}\right)$ & $10^{5} \mathrm{Q}\left(\mathrm{S}^{\mathrm{n}} \Omega^{-1} \mathrm{~cm}^{-2}\right)$ & $n$ & $C_{\mathrm{dl}}\left(\mu \mathrm{F} \mathrm{cm} \mathrm{cm}^{-2}\right)$ & $\operatorname{IE}(\%)$ \\
\hline 0 & $127.8 \pm 0.47$ & 50 & $0.83 \pm 0.51$ & 289.4 & - \\
200 & $190.3 \pm 0.70$ & 41 & $0.84 \pm 0.51$ & 255.6 & 33 \\
400 & $288.8 \pm 1.00$ & 19 & $0.86 \pm 0.50$ & 124.3 & 56 \\
600 & $480.5 \pm 0.77$ & 16 & $0.78 \pm 0.50$ & 80.9 & 73 \\
800 & $638.0 \pm 0.93$ & 10 & $0.82 \pm 0.50$ & 54.8 & 80 \\
900 & $952.5 \pm 0.73$ & 9 & $0.76 \pm 0.50$ & 40.5 & 86 \\
\hline
\end{tabular}

Fig. 8 Equivalent circuit used to fit the capacitive loop

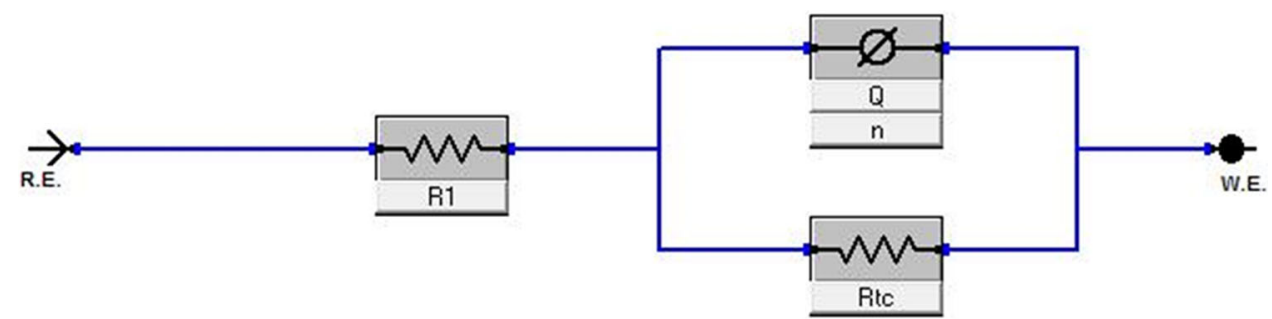

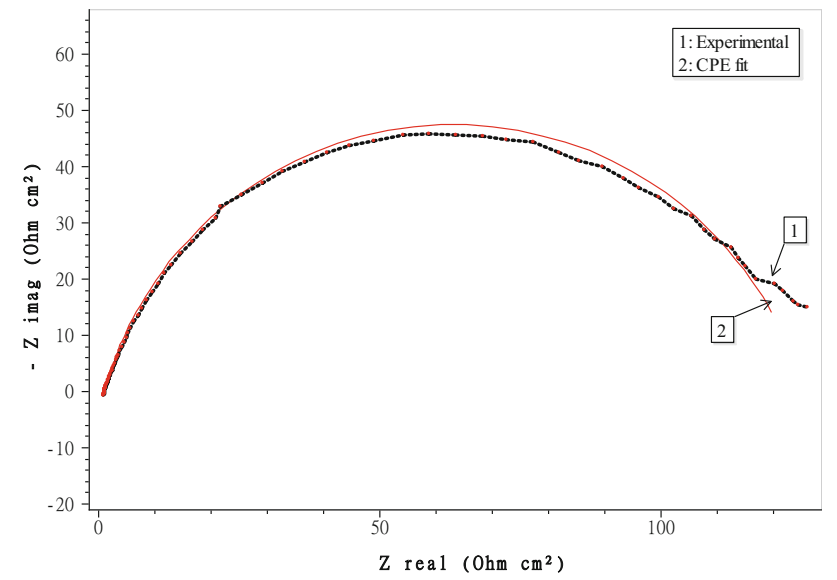

Fig. 9 Nyquist plot of carbon steel (X52) in $1 \mathrm{M} \mathrm{HCl}$

values, derived from the CPE parameters. Furthermore, the estimates of the margins of error calculated for the parameters are presented in Table 8.

From the impedance parameters (Table 8), it is clear that the $R_{\mathrm{ct}}$ values increase with inhibitor concentration, and thus the inhibition efficiency rises to $86 \%$ at $900 \mathrm{mg} \mathrm{L}^{-1}$. The values of double-layer capacitance are also brought down to the maximum extent in the presence of SSE and the decrease in the values of $C_{\mathrm{dl}}$ follows the order similar to that obtained for $i_{\text {corr }}$ in this study. The decrease in $C_{\mathrm{dl}}$ is due to the adsorption of the SSE on carbon steel (X52) surface leading to the formation of a film from the acidic solution [33].

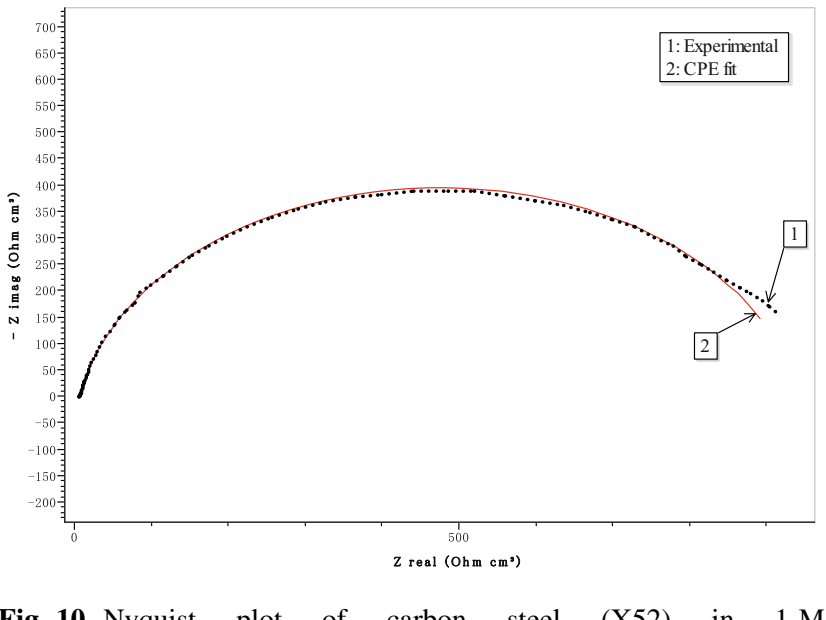

Fig. 10 Nyquist plot of
$\mathrm{HCl}+900 \mathrm{mg} \mathrm{L}^{-1}$ of SSE

\section{Scanning electron microscope (SEM)}

Scanning electron microscope (SEM) images were taken to study the surface morphology of carbon steel (X52) in the absence and presence of SSE as an inhibitor. SEM images are given in Fig. 11. The carbon steel (X52) sample dipped in the inhibitor solutions has apparently smooth surface when compared with that of rough corroded specimen immersed in $\mathrm{HCl}$ alone. This improvement in surface morphology indicates the formation of a protective layer on the steel surface which decreases the material degradation [40]. 

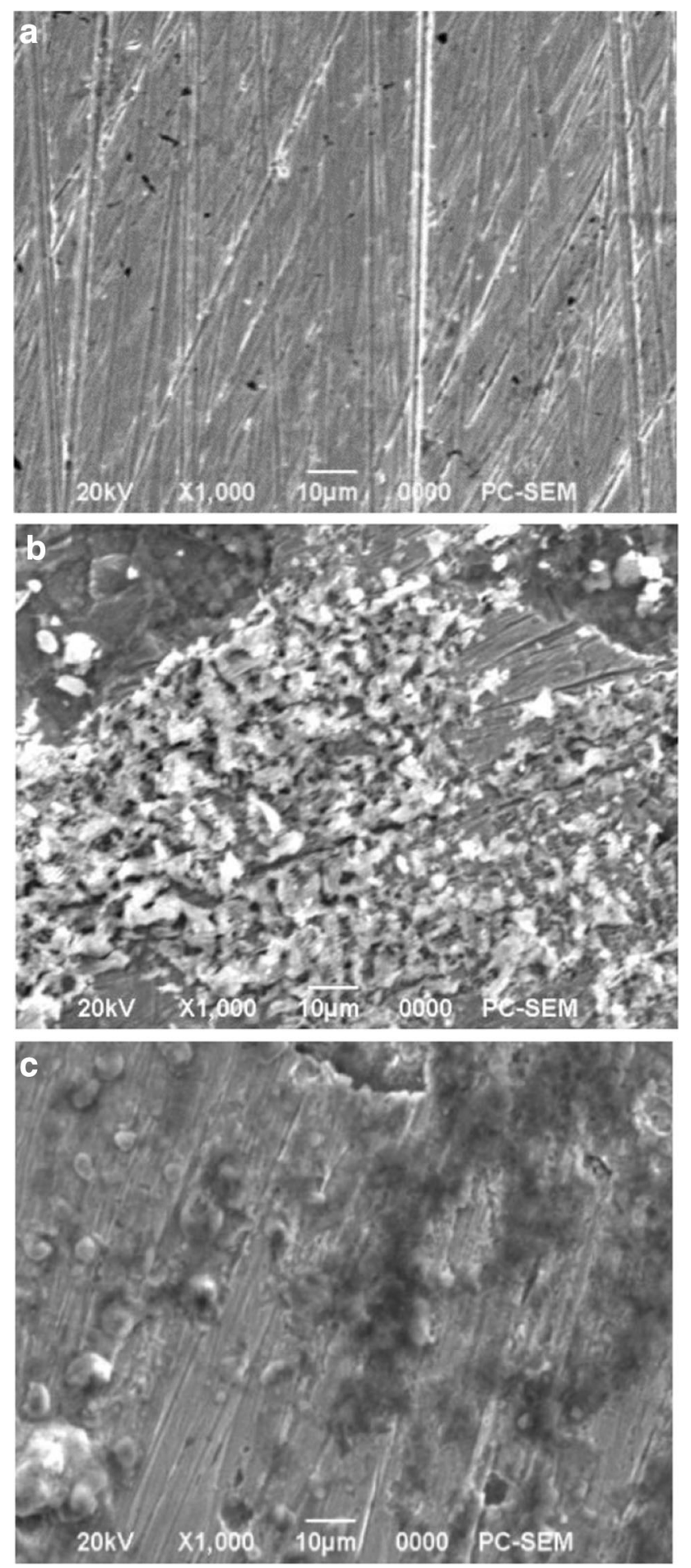

Fig. 11 SEM images of, a abraded carbon steel (X52), b carbon steel (X52) immersed in $1 \mathrm{M} \mathrm{HCl}$ solution, $\mathbf{c}$ carbon steel (X52) immersed in $1 \mathrm{M} \mathrm{HCl}$ containing $900 \mathrm{mg} \mathrm{L}^{-1}$ of SSE

\section{Inhibition mechanism}

Most of the Saccocalyx satureioides extract constituents are hydroxy aromatic compounds, such as piceol, vanillin, ferulic aldehyde and flavonoids [11]. The corresponding chemical structures of these compounds are shown in Fig. 12. Inspection of the figure reveals that these compounds contain $\mathrm{O}$ in functional groups, aromatic rings and $O$-heterocyclic rings, which encounter the general characteristics of typical corrosion inhibitors.

In acidic solution, the oxygen atom of these chemical compounds can be protonated easily, leading to positively charged inhibitor species. The charge of the metal surface is determined by the value of $E$ corr $-E \mathrm{q}=0$. The $E \mathrm{q}=0$ of iron is $-530 \mathrm{mV}$ vs. SCE in $\mathrm{HCl}$ [38]. In this system, the value of Ecorr is $463 \mathrm{mV}$ vs. SCE. The steel surface charges positive in $1 \mathrm{M} \mathrm{HCl}$ solution because of the value of $E$ corr $-E q=0>0$. Thus, in acid solution, the metal surface is negatively charged due to the specifically adsorbed chloride anions on the metal surface. Then the adsorption can occur between positively charged inhibitor molecules and negatively charged metal surface leading to physisorption of the inhibitor molecules. Further, when the protonated molecules are adsorbed on the steel surface, a coordinate band may be formed by partial transference of electrons from oxygen atoms to vacant $d$ orbits of iron.

\section{Conclusion}

From the global experimental results the next conclusions can be summarized:

- Results obtained over weight loss measurements and electrochemical tests revealed that the ethyl acetate extract of Saccocalyx satureioides acts as efficient corrosion inhibitors of the carbon steel in acid solution.

- Potentiodynamic polarization measurements exhibit that SSE acts as a mixed-type inhibitor.

- The adsorption of SSE on the carbon steel (X52) surface follows Freundlich adsorption isotherm.

- The negative values of free energy of adsorption ( $\Delta G_{\text {ads }}^{0}$ ) specify that the adsorption process is spontaneous physically adsorbed on the carbon steel (X52) surface. 
<smiles>CC(=O)c1ccc(O)cc1</smiles>

1<smiles>COc1cc(C(C)=O)ccc1O</smiles>

2

3- $\mathrm{R}_{1}=\mathrm{H}, \quad \mathrm{R}_{2}=\mathrm{OH}, \mathrm{R}_{3}=\mathrm{OMe}$

$6-\mathrm{R}_{1}=\mathrm{OH}, \mathrm{R}_{2}=\mathrm{OMe}, \mathrm{R}_{3}=\mathrm{OMe}$

$9-\mathrm{R}_{1}=\mathrm{OH}, \quad \mathrm{R}_{2}=\mathrm{OH}, \mathrm{R}_{3}=\mathrm{OH}$

10- $\mathrm{R}_{1}=\mathrm{OH}, \quad \mathrm{R}_{2}=\mathrm{OH}, \mathrm{R}_{3}=\mathrm{H}$<smiles>[R]c1cc([R])c2c(c1)[C@H](O)[C@@H]([C@H]1CCc3c([R])cc(OC)cc3[C@@H]1O)CC2</smiles>

4- $\mathrm{R}=\mathrm{OMe}$

$5-\mathrm{R}=\mathrm{H}$<smiles>[R]c1cc(-c2cc(=O)c3c(O)c(OC)c(OC)c(OC)c3o2)ccc1O</smiles>

8 - $\mathrm{R}=\mathrm{OMe}$

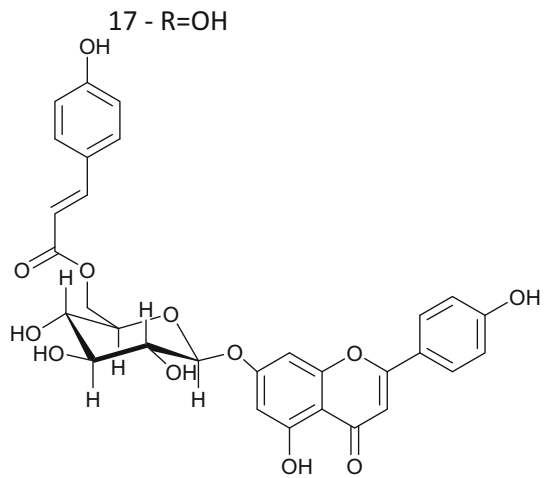

11- $\mathrm{R}_{1}=\mathrm{H}, \quad \mathrm{R}_{2}=\mathrm{H}$

12- $\mathrm{R}_{1}=\mathrm{Ac}, \quad \mathrm{R}_{2}=\mathrm{H}$,

13- $R_{1}=H, \quad R_{2}=A c$,

15- $R_{1}=A c, \quad R_{2}=A c$

7<smiles>O=c1c(O)c(-c2ccc(O)c(O)c2)oc2cc(O)cc(O)c12</smiles>

14<smiles>[R20]C[C@H]1O[C@H](Oc2cc(O)c3c(=O)cc(-c4ccc(O)cc4)oc3c2O)[C@H](C[C@H]2O[C@H](C[R20])[C@H](O)[C@@H](O)[C@H]2O)[C@H](O)[C@@H]1O</smiles>

Fig. 12 Structures of the isolated compounds from Saccocalyx satureioides 
Acknowledgments The authors want to thank the MESRES Algeria (Ministère de l'Enseignement Supérieur et de la Recherche Scientifique) for the financial support.

Open Access This article is distributed under the terms of the Creative Commons Attribution 4.0 International License (http://crea tivecommons.org/licenses/by/4.0/), which permits unrestricted use, distribution, and reproduction in any medium, provided you give appropriate credit to the original author(s) and the source, provide a link to the Creative Commons license, and indicate if changes were made.

\section{References}

1. Ji Gopal, Anjum Shadma, Sundaram Shanthi, Prakash Rajiv (2015) Musa paradisica peel extract as green corrosion inhibitor for mild steel in $\mathrm{HCl}$ solution. Corros Sci 90:107-117

2. Faustin M, Maciuk A, Salvin P, Roos C, Lebrini M (2015) Corrosion inhibition of C38 steel by alkaloids extract of Geissospermum laeve in $1 \mathrm{M}$ hydrochloric acid: electrochemical and phytochemical studies. Corros Sci 92:287-300

3. Umoren Saviour A, Obot Ime B, Madhankumar A, Gasem Zuhair M (2015) Performance evaluation of pectin as ecofriendly corrosion inhibitor for X60 pipeline steel in acid medium: experimental and theoretical approaches. Carbohydr Polym 124:280-291

4. Lecante A, Robert F, Blandinières PA, Roos C (2011) Anticorrosive properties of $S$. tinctoria and G. ouregou alkaloid extracts on low carbon steel. Curr Appl Phys 11:714-724

5. Pereira S, Pêgas M, Fernandez T, Magalhaes M, Schntag T, Lago D, Ferreira L, D'Elia E (2012) Inhibitory action of aqueous garlic peel extract on the corrosion of carbon steel in $\mathrm{HCl}$ solution. Corros Sci 65:360-366

6. Raja PB, Qureshi AK, Rahim AA, Osman H, Awang K (2013) Neolamarckia cadamba alkaloids as eco-friendly corrosion inhibitors for mild steel in $1 \mathrm{M} \mathrm{HCl}$ media. Corros Sci 69:292-301

7. Quezel P, Santa S (1963) Nouvelles flores de l'Algérie et des régions désertiques méridionales. T. II, CNRS, Paris

8. Laouer H, Akkal S, Debarnot C, Canard B, Meierhenrich UJ, Baldovini N (2006) Chemical composition and antimicrobial activity of the essential oil of Saccocalyx satureioides Coss. Et Dur. Nat Prod Commun 8:645-650

9. Bendahou M, Benyoucef M, Muselli A, Desjobert JM, Paolini J, Bernardini A (2008) Antimicrobial activity and chemical composition of Saccocalyx satureioides Coss. Et Dur. Essential oil and extract obtained by microwave extraction. Comparison with hydrodistillation. J Essent Oil Res 20:174-178

10. Zerroug MM, Laouer H, Strange RN, Nicklin J (2011) The effect of essential oil of Saccocalyx satureioides Coss. Et Dur. On the growth of and the production of solanapyrone A by Ascochyta Rabiei (Pass.) Labr. J Adv Environ Biol 5:501-506

11. Mohamadi S, Zhao M, Amrani A, Marchioni E, Zama D, Benayache F, Benayache S (2015) On-line screening and identification of antioxidant phenolic compounds of Saccocalyx satureioides Coss. et Dur. Ind Crops Prod 76:910-919

12. Akkal S, Louaar S, Benahmed M, Laouer H, Duddeck H (2010) A new isoflavone glycoside from the aerial parts of Retama sphaerocarpa. Chem Nat Compd 46:719-721

13. Benahmed M, Akkal S, Louaar S, Laouer H, Duddeck H (2006) A new furanocoumarin glycoside from Carum montanum (Apiaceae). Biochem Syst Ecol 34:645-647

14. Djeddi N, Benahmed M, Akkal S, Laouer H, Makhloufi E, Gherraf N (2014) Study on methylene dichloride and butanolic extracts of Reuteralutea (Apiaceae) as effective corrosion inhibitions of carbon steel in $\mathrm{HCl}$ solution. Res Chem Intermed. doi:10.1007/s11164-014-1555-3

15. El ouariachi E, Hammouti B, Paolini J, Bouyanzer A, Desjobert J-M, Majidi L, Salghi R, Costa J (2015) Inhibition of corrosion of mild steel in $1 \mathrm{M} \mathrm{HCl}$ by the essential oil or solvent extracts of Ptychotis verticillata. Res Chem Intermed 41:935-946

16. El Ouadi Y, Bouyanzer A, Desjobert J-M, Hammouti B, Ben Hadda T, Costa J, Jodeh S, Majidi L, Chetouani A, Warad I, Paolini J, Mabkhot Y (2014) Evaluation of Pelargonium extract and oil as eco-friendly corrosion inhibitor for steel in acidic chloride solutions and pharmacological properties. Res Chem Intermed. doi:10.1007/s11164-014-1802-7

17. Bouyanzer A, Hammouti B, Majidi L (2006) Pennyroyal oil from Mentha pulegium as corrosion inhibitor for steel. Mater Lett 60:2840-2843

18. Hamdy A, El-Gendy NSh (2013) Thermodynamic, adsorption and electrochemical studies for corrosion inhibition of carbon steel by henna extract in acid medium. Egypt $J$ Petrol 22:17-25

19. Lebrini M, Robert F, Lecante A, Roos C (2011) Corrosion inhibition of $\mathrm{C} 38$ steel in $1 \mathrm{M}$ hydrochloric acid medium by alkaloids extract from Oxandra asbeckii plant. Corros Sci 53:687-695

20. Tang Y, Zhang F, Hu S, Cao Z, Wu Z, Jing W (2013) Novel benzimidazole derivatives as corrosion inhibitors of mild steel in the acidic media. Part I: gravimetric, electrochemical, SEM and XPS studies. Corros Sci 74:271-281

21. El Bribri A, Tabyaoui M, Tabyaoui B, El Attari H, Bentiss F (2013) The use of Euphorbia falcata as eco-friendly corrosion inhibitor of carbon steel in hydrochloric acid solution. Mater Chem Phys 141:240-247

22. Yaro AS, Khadom AA, Wael RK (2013) Apricot juice as green corrosion inhibitor of mild steel in phosphoric acid. Alex Eng $\mathrm{J}$ 52:129-135

23. Li X, Deng S, Fu H (2012) Inhibition of the corrosion of steel in $\mathrm{HCl}, \mathrm{H}_{2} \mathrm{SO}_{4}$ solutions by bamboo leaf extract. Corros Sci 62:163-175

24. Li L, Zhang X, Lei J, He J, Zhang S, Pan F (2012) Adsorption and corrosion inhibition of Osmanthus fragran leaves extract on carbon steel. Corros Sci 63:82-90

25. Deyab MA, Abd El-Rehim SS (2013) Effect of succinic acid on carbon steel corrosion in produced water of crude oil. J Taiwan Inst Chem Eng. doi:10.1016/j.jtice.2013.09.004

26. Ostovari A, Hoseinieh SM, Peikari M, Shadizadeh SR, Hashemi SJ (2009) Corrosion inhibition of mild steel in $1 \mathrm{M} \mathrm{HCl}$ solution by henna extract: a comparative study of the inhibition by henna and its constituents (Lawsone, gallic acid, $\alpha$-D-glucose and tannic acid). Corros Sci 51:1935-1949

27. Pournazari Sh, Moayed MH, Rahimizadeh M (2013) In situ inhibitor synthesis from admixture of benzaldehyde and benzene1,2-diamine along with $\mathrm{FeCl}_{3}$ catalyst as a new corrosion inhibitor for mild steel in $0.5 \mathrm{M}$ sulphuric acid. Corros Sci 71:20-31

28. Tebbji K, Faska N, Tounsi A, Oudda H, Benkaddour M, Hammouti B (2007) The effect of some lactones as inhibitors for the corrosion of mild steel in $1 \mathrm{M}$ hydrochloric acid. Mater Chem Phys 106:260-267

29. Behpour M, Ghoreishi SM, Khayatkashani M, Soltani N (2012) Green approach to corrosion inhibition of mild steel in two acidic solutions by the extracts of Punicagranatum peel main constituents. Mater Chem Phys 131:621-633

30. Hodaifa G, Ochando-Pulido JM, Alami SBD, Rodriguez-Vives S, Martinez-Ferez A (2013) Kinetic and thermodynamic parameters of iron adsorption onto olive stones. Ind Crop Prod 49:526-534

31. Zarrok H, Zarrouk A, Hammouti B, Salghi R, Jama C, Bentiss F (2012) Corrosion control of carbon steel in phosphoric acid by purpald-weight loss, electrochemical and XPS studies. Corros Sci 64:243-252 
32. Bouklah M, Benchat N, Hammouti B, Aouniti A, Kertit S (2006) Thermodynamic characterization of steel corrosion and inhibitor adsorption of pyridazine compounds in $0.5 \mathrm{M} \mathrm{H}_{2} \mathrm{SO}_{4}$. Mater Lett 60:1901-1905

33. Fouda AS, Wahed HA (2011) Corrosion inhibition of copper in $\mathrm{HNO}_{3}$ solution using thiophene and its derivatives. Arab J Chem. doi:10.1016/arabjc2011.02.014

34. Singh AK, Quraishi MA (2010) Effect of cefazolin on the corrosion of mild steel in $\mathrm{HCl}$ solution. Corros Sci 52:152-160

35. Ahamad I, Prasad R, Quraishi MA (2010) Adsorption and inhibitive properties of some new Mannich bases of Isatinderivaties on corrosion of mild steel in acidic media. Corros Sci 52:1472-1481

36. Bobina M, Kellenberger A, Millet JP, Muntean C, Vaszilcsin N (2013) Corrosion resistance of carbon steel in weak acid solutions in the presence of L-histidine as corrosion inhibitor. Corros Sci 69:389-395

37. Moretti G, Guidi F, Fabris F (2013) Corrosion inhibition of the mild steel in $0.5 \mathrm{M} \mathrm{HCl}$ by 2-butyl-hexahydropyrrolo [1,2-b] [1, 2] oxazole. Corros Sci 76:206-218

38. Deng S, Li X (2012) Inhibition by Ginkgo leaves extract of the corrosion of steel in $\mathrm{HCl}$ and $\mathrm{H}_{2} \mathrm{SO}_{4}$ solutions. Corros Sci 55:407-415

39. Hazwan Hussin M, Jain Kassim M (2011) The corrosion inhibition and adsorption behavior of Encaria gambir extract on mild steel in $1 \mathrm{M} \mathrm{HCl}$. Mater. Chem Phys 125:461-468

40. Gualdrón AF, Becerra EN, Peña DY, Gutiérrez JC (2013) Inhibitory effect of Eucalyptus and Lippia Alba essential oils on the corrosion of mild steel in hydrochloric acid. J Mater Environ Sci $4: 143-158$ 